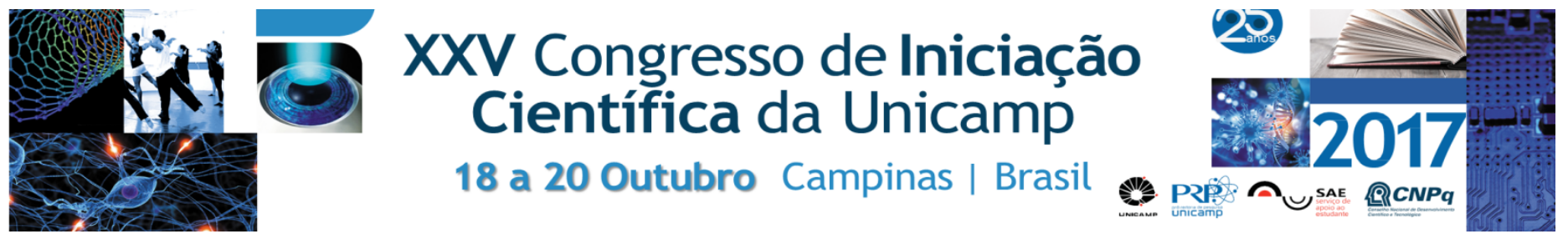

\title{
Metodologia para a síntese de nanofios de prata não suportados para uso como revestimento condutivo transparente.
}

\section{Daniel H. Caous, Gustavo Doubek*}

\section{Resumo}

O objetivo do trabalho foi o desenvolvimento do procedimento de síntese de nanofios de prata e avaliar a influência dos parâmetros de síntese em sua morfologia final. O material tem potencial para ser utlizado como revestimento condutivo transparente na aplicação em telas touch-screen, substituindo o oxido de estanho dopado com índio.

\section{Palavras-chave:}

Nanofios, Sintese, Revestimento condutivo.

\section{Introdução}

A aplicação e uso de telas sensíveis ao toque torna-se cada vez mais comum, sendo amplamente utilizada em smartphones e computadores. Essa tecnologia aumenta a imersão e facilita o uso dos equipamentos ${ }^{1}$. As telas capacitivas são as mais populares e utilizadas em virtude da sua precisão e qualidade de uso ${ }^{1}$. Porém combinar transparência com condutividade elétrica é um grande desfio para a ciência dos materiais. Atualmente apenas o oxido de estanho dopado com índio (ITO) é usado comercialmente e representa uma grande preocupação para a indústria devido à limitada oferta do índio. Alternativas ao ITO empregam nanotubos de carbono ou grafeno e nanofios de prata. Nesse projeto, foi estudado o método de síntese de nanofios de prata e sua aplicação em superfície para se avaliar parâmetros de síntese e sua influência na geometria final. Espera-se obter um material transparente e condutivo para que as telas sejam operacionais.

\section{Resultados e Discussão}

Para a realização dos experimentos em laboratório utilizou-se etilenoglicol como meio reacional, no qual o nitrato de prata e a polivinilpirrolidona (PVP) solubilizados foram adicionados gota a gota, seguindo a metodologia de Walker et $\mathrm{al}^{2}$. Variou-se a temperatura de síntese e a concentração de PVP de modo a avaliar as influencias dos parâmetros. A temperatura adotada como referencia foi a de $160^{\circ} \mathrm{C}$. A partir da Figura 1 nota-se uma boa dispersão dos nanofios, com tamanhos suficientes para formar uma rede de nanofios condutivos. As imagens foram obtidas no MEV. Esse resultado indica, pela inspeção visual, que de fato forma-se uma rede de nanofios de prata que podem apresentar as propriedades esperadas para aplicação em telas touchscreen - condutividade e transparência. Nas sínteses realizadas notou-se que a presença em excesso de paládio - sementes para nucleação dos nanofios - foi negativa, pois ocorria a deposição de prata sem a formação de nanofios não ocorrendo o crescimento.

A Figura 1, realizada nas condições padrões, ilustra a melhor condição obtida, em que se formou uma rede densa e distribuída de nanofios, o que representa o melhor cenário visando à aplicação desejada. Quando se diminui a concentração de PVP houve uma diminuição tanto no comprimento como no diâmetro dos nanofios. Tal efeito pode ser explicado pela diminuição da passivação do meio, proporcionada pelo polímero possibilitando maiores pontos de nucleação em que não houve o crescimento dos nanofios.

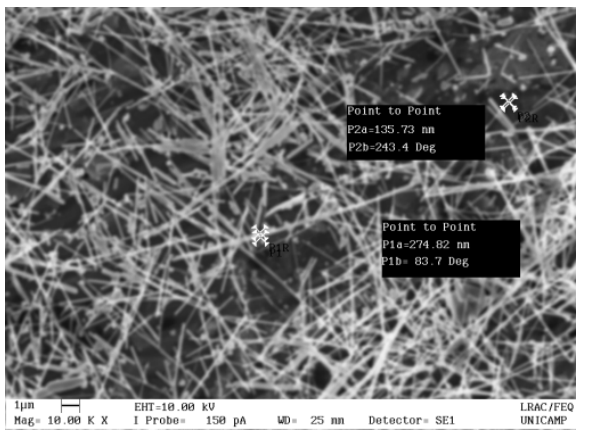

Figura 1. Síntese nas condições padrões.

Para a diminuição da temperatura a $130^{\circ} \mathrm{C}$ ocorreu um fato inesperado. Não houve a formação dos nanofios, mas uma superfície metálica de aspecto esponjoso, como mostra a Figura 2. Uma pesquisa bibliografica ${ }^{3}$ indicou que tal material possui aplicação como catalisador, pois sua superfície apresenta grande área superficial. Tal síntese abre uma nova aplicação para síntese, variando-se apenas uma condição de reação.

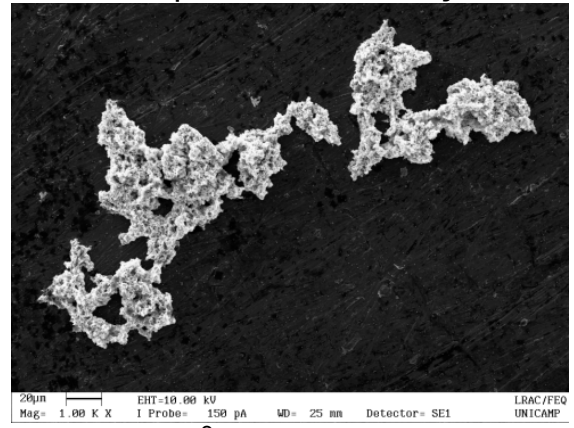

Figura 2. Síntese a $130^{\circ} \mathrm{C}$

\section{Conclusões}

A metodologia utilizada foi adequada para a obtenção do material, sendo de fácil aplicação. Foi possível medir os impactos das condições de síntese sobre a geometria dos nanofios sintetizados, como tamanho e quantidade de nanofios.

${ }^{1}$ Bakhtiyari, K., Taghavi, M. \& Husain, H. Hybrid affective computing--keyboard, mouse and touch screen: from review to experiment. Neural Comput. Appl. 26, 1277-1296 (2014).

${ }^{2}$ Walker, G. A review of technologies for sensing contact location on the surface of a display. J. Soc. Inf. Disp. 20, 413-440 (2012).

${ }^{3}$ Muthusamy, E, atla, S K, "Template free and polymer free metal, nanosponge and a process thereof".

DOI: 10.19146/pibic-2017-77842 